https://helda.helsinki.fi

\title{
Thermoresponsive Pentablock Copolymer on Silica : \\ Temperature Effects on Adsorption, Surface Forces, and Friction
}

Dobryden, Illia

2019-01-22

Dobryden , I, Ruiz, M C , Zhang , X, Dedinaite , A, Wieland, D C F , Winnik, F M \& Claesson, P M 2019 , ' Thermoresponsive Pentablock Copolymer on Silica : Temperature Effects on Adsorption, Surface Forces, and Friction ' , Langmuir, vol. 35 , no. 3 , pp. 653-661 . https://doi.org/10.1021/acs.langmuir.8b03729

http://hdl.handle.net/10138/301153

https://doi.org/10.1021/acs.langmuir.8b03729

other

publishedVersion

Downloaded from Helda, University of Helsinki institutional repository.

This is an electronic reprint of the original article.

This reprint may differ from the original in pagination and typographic detail.

Please cite the original version. 


\title{
Thermoresponsive Pentablock Copolymer on Silica: Temperature Effects on Adsorption, Surface Forces, and Friction
}

\author{
Illia Dobryden, ${ }^{*}{ }^{\dagger}$ Maria Cortes Ruiz, ${ }^{\ddagger}$ Xuwei Zhang, ${ }^{\S}$ Andra Dėdinaitè, ${ }^{\dagger, \nabla}$ D. C. Florian Wieland, ${ }^{\|}$ \\ Françoise M. Winnik, ${ }^{\perp, \# \odot}$ and Per M. Claesson ${ }^{\dagger, \nabla}$ \\ ${ }^{\dagger}$ School of Engineering Sciences in Chemistry, Biotechnology and Health, Department of Chemistry, Division of Surface and \\ Corrosion Science, KTH Royal Institute of Technology, SE-10044 Stockholm, Sweden \\ ${ }^{\ddagger}$ Department of Chemical Engineering, Grove School of Engineering, the City College of New York, New York, New York 10031, \\ United States \\ ${ }^{\S}$ Department of Chemistry, University of Montreal, CP 6128 Succursale Centre Ville, Montreal, Québec H3C3 J7, Canada \\ "Helmholtz Zentrum Geesthacht, Institute for Materials Research, Max-Planck Straße 1, 21502 Geesthacht, Germany \\ ${ }^{\perp}$ Department of Chemistry, University of Helsinki, P.O. Box 55, Helsinki FI00014, Finland \\ \#International Center for Materials Nanoarchitectonics (MANA), National Institute for Materials Science (NIMS), 1-1 Namiki, \\ Tsukuba 305-0044, Japan \\ ${ }^{\nabla}$ Division of Bioscience and Materials, RISE Research Institutes of Sweden, SE-114 86 Stockholm, Sweden
}

Supporting Information

\begin{abstract}
The adsorption of hydrophilic or amphiphilic multiblock copolymers provides a powerful means to produce well-defined "smart" surfaces, especially if one or several blocks are sensitive to external stimuli. We focus here on an $\mathrm{A}-\mathrm{B}-\mathrm{A}-\mathrm{B}-\mathrm{A}$ copolymer, where $\mathrm{A}$ is a cationic poly((3acrylamido-propyl)-trimethylammonium chloride) (PAMPTMA) block containing 15 (end blocks) or 30 (middle block) repeat units and $\mathrm{B}$ is a neutral thermosensitive water-soluble poly(2-isopropyl-2-oxazoline) (PIPOZ) block with 50 repeat units. X-ray reflectivity and quartz crystal microbalance with dissipation monitoring were employed to study the adsorption of PAMPTMA $_{15}-\mathrm{PIPOZ}_{50}-\mathrm{PAMPTMA}_{30}-\mathrm{PIPOZ}_{50}-$ $\mathrm{PAMPTMA}_{15}$ on silica surfaces. The latter technique was

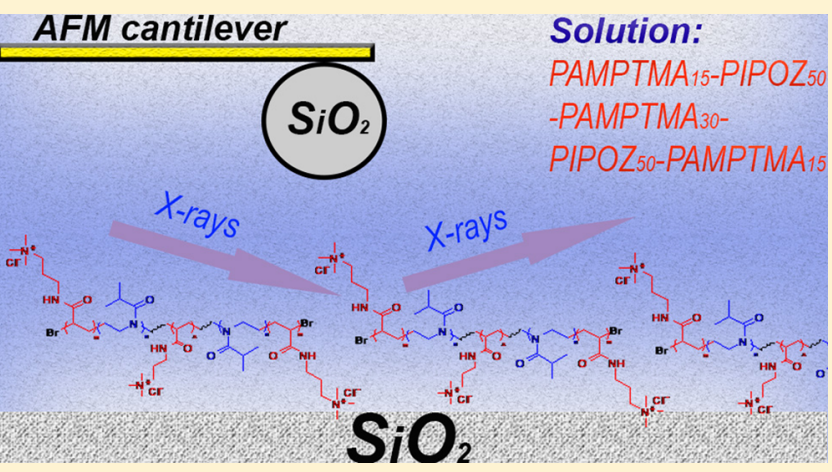
employed at different temperatures up to $50{ }^{\circ} \mathrm{C}$. Surface forces and friction between the two silica surfaces across aqueous pentablock copolymer solutions at different temperatures were determined with the atomic force microscopy colloidal probe force and friction measurements. The cationic pentablock copolymer was found to have a high affinity to the negatively charged silica surface, leading to a thin $(2 \mathrm{~nm})$ and rigid adsorbed layer. A steric force was encountered at a separation of around $3 \mathrm{~nm}$ from hard wall contact. A capillary condensation of a polymer-rich phase was observed at the cloud point of the solution. The friction forces were evaluated using Amontons' rule modified with an adhesion term.
\end{abstract}

\section{INTRODUCTION}

Responsive hydrophilic or amphiphilic copolymers have emerged recently as useful materials, in particular as delivery systems of drugs $^{1}$ and pentablock copolymers, which have been used for the delivery of sensitive active molecules, such as siRNA. ${ }^{2}$ The distinctive advantage of these polymers arises from the possibility of changing the balance between blocks having different functionalities. With the rapid development of controlled polymerization techniques and of "click chemistry", the range of pentablock copolymers attainable seems limitless. It is now possible to prepare complex multiblock copolymers of controlled composition, block sequence, and block length. These features are useful in the design of smart surface layers ${ }^{4}$ for sensors, nanoactuators, and microfluidic devices. ${ }^{4-7}$
Numerous opportunities arise since blocks can be responsive to $\mathrm{pH}$, salt concentration, temperature, redox conditions, or other environmental stimuli.

The adsorption of pentablock copolymers on surfaces also offers the opportunity to address fundamental questions in surface science related to the differences between loopdominated and tail-dominated surfaces. For instance, it has been proposed that loop-dominated copolymer structures can have better lubrication properties than the tail-dominated ones $^{8,9}$ due to lower chain interpenetration between the

Received: November 5, 2018

Revised: December 24, 2018

Published: January 3, 2019 
opposing surface layers. This has indeed been reported for loop-forming triblock copolymers. ${ }^{10,11}$ For pentablock copolymers, this question can be approached systematically by comparing the layer properties of a diblock copolymer consisting of a cationic block (A) and a neutral block (B) on a negatively charged surface with those of a pentablock copolymer consisting of the same blocks in the $\mathrm{A}-\mathrm{B}-\mathrm{A}-\mathrm{B}-\mathrm{A}$ arrangement. In the case of the diblock copolymer, even though the nonionic block may have a weak tendency to adsorb on the negatively charged surface, it tends to form tails, and more so at higher $\mathrm{pH}$ where the segregation between the cationic block and the nonionic block is larger. ${ }^{12}$ In contrast, in the case of the $\mathrm{A}-\mathrm{B}-\mathrm{A}-\mathrm{B}-\mathrm{A}$ copolymer, the $\mathrm{B}$ block is expected to form primary loops, since the two nonionic $\mathrm{B}$ blocks are linked on both ends to the cationic block.

An et al. studied the adsorption of a diblock copolymer consisting of a neutral water-soluble poly(2-isopropyl-2oxazoline) (PIPOZ) $)_{60}$ block and a cationic poly((3-acrylamidopropyl)-trimethylammonium chloride) ${ }_{17}$ (PAMPTMA) block, using atomic force microscopy (AFM), quartz crystal microbalance with dissipation (QCM-D), and ellipsometry. ${ }^{12-14}$ They found that the adsorbed mass on silica surfaces increases slightly with increasing polymer concentration (10$100 \mathrm{ppm}$ ) and, more significantly, with increasing $\mathrm{pH}$, due to the $\mathrm{pH}$-dependence of the silica surface charge density. A pronounced increase in the adsorbed mass was observed with increasing temperature, due to the worsening of the solvent quality of water for PIPOZ, and as a consequence the diblock copolymer was found to phase separate at $46{ }^{\circ} \mathrm{C}$. ${ }^{13}$ Above the bulk phase separation temperature, aggregate deposition occurred on the surface. ${ }^{13}$ The interaction between surfaces carrying such adsorbed layers immersed in water changed from purely repulsive at low temperature to partly attractive at higher temperatures as a result of the worsening solvent conditions. ${ }^{12}$ The friction force increased with temperature up to $45{ }^{\circ} \mathrm{C}$ with an unexpected lowering of the friction at $50{ }^{\circ} \mathrm{C}$, the highest temperature probed in the study, presumably due to PIPOZ chain crystallization in aqueous solution above the bulk phase separation temperature. It was also demonstrated that the presence of the polymer in solution during the temperature variation strongly affects normal and friction forces. $^{12,13}$

Here, we examine the adsorption of the pentablock copolymer PAMPTMA $15-$ PIPOZ $_{50}-$ PAMPTMA $_{30}-$ PIPOZ $_{50}-$ PAMPTMA $_{15}$ (Figure 1) on silica. Specifically, we study the surface and friction forces between the layers of the

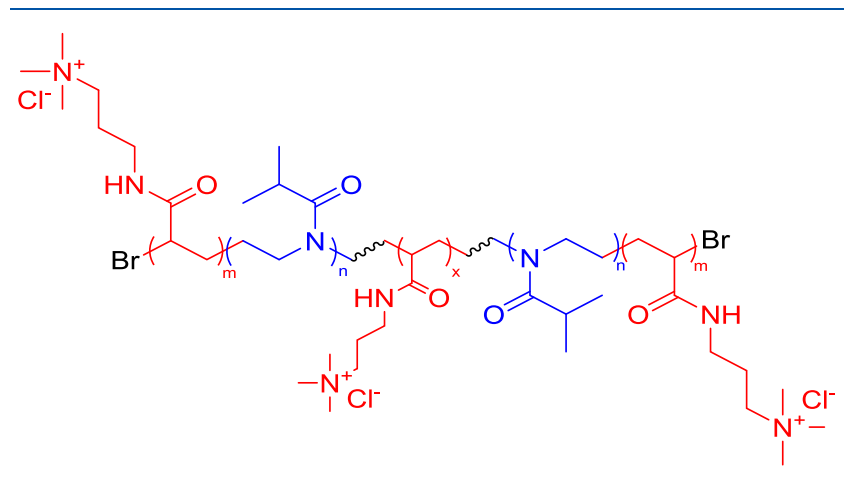

Figure 1. Chemical structure of the pentablock copolymer, where the PAMPTMA blocks are drawn in red and the PIPOZ blocks are drawn in blue, with $m=15, n=50$, and $x=30$. pentablock copolymer immersed in a solution containing this polymer by utilizing the AFM colloidal probe technique. The three cationic blocks have a high affinity to the surface, whereas the two PIPOZ blocks have significantly less surface affinity. Due to the thermosensitivity of the PIPOZ blocks, the aqueous pentablock copolymer solution undergoes a phase transition upon heating past a temperature in the vicinity of $55^{\circ} \mathrm{C}$. The friction forces between the two layers were monitored also as a function of temperature in the range of $23-55{ }^{\circ} \mathrm{C}$. The pentablock copolymer adsorption onto a negatively charged silica surface in water was also investigated by X-ray reflectivity (XRR) and QCM-D. Although a number of hydrophilic pentablock copolymers have been described, ${ }^{15}$ experimental studies of the interfacial properties of pentablock copolymers containing thermoresponsive blocks remain scarce, ${ }^{16,17}$ and we are not aware of any previous study of the surface and friction forces for such systems.

\section{MATERIALS AND METHODS}

Materials. The chemical structure of PAMPTMA $\mathrm{P}_{15}-\mathrm{PIPOZ}_{50}-$ PAMPTMA $_{30}-$ PIPOZ $_{50}-$ PAMPTMA $_{15}$ is shown in Figure 1. This pentablock copolymer structure was chosen to allow comparison with a previously studied diblock copolymer with similar block lengths, $\mathrm{PAMPTMA}_{17}-\mathrm{PIPOZ}_{60}$. It was obtained by click ligation of an $\alpha, \omega$ dipropargyl-PAMPTMA ${ }_{30}$ with azide-terminated PAMPTMA $_{15}-b$ $\mathrm{PIPOZ}_{50}$ as described in detail elsewhere (manuscript in preparation). $\mathrm{NaCl}(\geq 99.5 \%$, Sigma-Aldrich) was used to prepare aqueous $\mathrm{NaCl}$ solutions of $1 \mathrm{mM}$ concentration with and without the pentablock copolymer using Milli-Q water (Millipore, Molsheim, France) with 18.2 $\mathrm{M} \Omega \times \mathrm{cm}$ resistivity and the total organic carbon content of less than $1 \mathrm{ppb}$. A $500 \mathrm{ppm}$ (by weight) pentablock copolymer solution was first prepared. Then, this solution was further diluted using $1 \mathrm{mM}$ $\mathrm{NaCl}$ to reach 10,50, and $100 \mathrm{ppm}$ concentrations for QCM-D and AFM measurements. The $\mathrm{pH}$ of the solutions was adjusted to $\mathrm{pH} 9$ by adding $\mathrm{NaOH}(1 \mathrm{M})$ and $\mathrm{HCl}(0.6 \mathrm{M})$. Silicon wafers with a $33 \mathrm{~nm}$ silica layer were purchased from Wafer net (Germany) and were then cut into squares of about $12 \mathrm{~mm}$ for the AFM measurements. The cloud point of PAMPTMA $15-\mathrm{PIPOZ}_{50}-\mathrm{PAMPTMA}_{30}-\mathrm{PIPOZ}_{50}-$ $\mathrm{PAMPTMA}_{15}$ in this solution was estimated by visual inspection and the solution was found to become turbid at $55^{\circ} \mathrm{C}$.

Quartz Crystal Microbalance with Dissipation (QCM-D). The QCM-D technique allows measurements of changes in frequency and dissipation at the fundamental and overtone oscillation of a quartz sensor that occurs as a mass is added to the surface due to adsorption. In this study we employed a Q-sense E4 microbalance (Biolin Scientific, Gothenburg, Sweden) using sensors with silica coating (QSX-303, Biolin Scientific). All parts of the QCM-D cell were cleaned using 2\% Deconex solution (Borer Chemie AG, Switzerland) and sonicated for half an hour, followed by extensive rinsing with Milli-Q water. The QSX-303 sensors were cleaned using $2 \%$ Hellmanex solution (Hellma $\mathrm{GmbH}$ ) for half an hour without sonication. Next, the sensors were extensively rinsed with Milli-Q water and dried using a filtered nitrogen jet. All cleaning and assembly operations were carried out in a laminar flow cabinet.

Baselines for the oscillation frequencies and dissipation values were first established in $1 \mathrm{mM} \mathrm{NaCl}$ solution at $\mathrm{pH} 9$, in the absence of any polymer, at a temperature of $25{ }^{\circ} \mathrm{C}$. Next, the polymer solution in $\mathrm{NaCl}$ at $\mathrm{pH} 9$ was injected into the QCM-D cell and the changes in frequency and dissipation values relative to the baselines were recorded. The adsorption was also studied at $50{ }^{\circ} \mathrm{C}$, which is slightly below the cloud point of the pentablock polymer solution. The solutions were preheated to this temperature prior to being injected into the cell. The flow during measurements was set to $100 \mu \mathrm{L} / \mathrm{min}$. The Sauerbrey model, ${ }^{18}$ based on the assumption that the sensor frequency change is only affected by the mass adsorbed to the sensor surface, $\left(\Gamma_{\text {QCM-D }}\right)$ was employed. This model is valid for thin and rigid layers, and when this condition is fulfilled, the mass oscillating with 
the crystal (polymer and associated solvent), $\Gamma_{\mathrm{OCM}-\mathrm{D}}$, can be calculated as

$$
\Gamma_{\mathrm{QCM}-\mathrm{D}}=\frac{-C \times \Delta f}{n}
$$

where $n$ is the overtone number, $\Delta f$ is the frequency change, and $C$ is a characteristic constant for the sensor used, and for these sensors it is $0.177 \mathrm{mg} / \mathrm{m}^{2} / \mathrm{Hz}$.

To employ the Sauerbrey model at first may appear surprising since the pentablock copolymer is expected to form loops at the surfaces due to the presence of the PIPOZ block, and thus, such adsorbed layers could be expected to show viscoelastic properties. However, we found that the Sauerbrey model is appropriate for this system and we will return to this finding in the Results section.

X-ray Reflectivity Measurements. X-ray reflectivity, XRR, measurements allow the determination of the laterally averaged structure of thin films in the perpendicular direction of an interface. The measurements reported herein were performed at a custom-built laboratory reflectometer at the NanoLab, DESY Hamburg, with a molybdenum anode providing an X-ray energy of $17.6 \mathrm{keV}$. A reflectivity sample cell that allowed the use of a silicon wafer in solution was employed. The X-ray path length was $1 \mathrm{~cm}$ and the window thickness was $0.1 \mathrm{~mm}$. The sample cell was printed with a three-dimensional printer, Ultimaker $2+$, and consisted of acrylonitrile, butadiene, and styrene monomers (ABS plastics). The samples were studied at $22{ }^{\circ} \mathrm{C}$. The sample cell and the silicon wafers $(10 \mathrm{~mm}$ $\times 10 \mathrm{~mm}$ ) were cleaned using $2 \%$ Hellmanex solution, followed by rinsing with Milli- $Q$ water. The polymer was dissolved in a $0.1 \mathrm{mM}$ $\mathrm{NaCl}$ solution. This solution was adjusted to $\mathrm{pH} 9$ by adding $\mathrm{NaOH}$ (1 M) and $\mathrm{HCl}(0.6 \mathrm{M})$.

In an XRR experiment, the specular reflected intensity $I$ of the Xray beam is recorded as a function of the incident angle $\theta$. The reflected intensity is determined by the average electron density $\left(\rho_{\mathrm{e}}\right)$ of the sample perpendicular to the surface and given by

$$
I\left(q_{z}\right)=R_{\mathrm{F}}\left|\frac{1}{\rho_{\mathrm{e}}(z \rightarrow \infty)} \int_{-\infty}^{\infty} \frac{\mathrm{d} \rho_{\mathrm{e}}}{\mathrm{d} z} \mathrm{e}^{i q z}\right|^{2}
$$

where $q$ denotes the modulus of the wave vector transfer perpendicular to the surface and is given by

$$
q_{z}=\frac{4 \pi}{\lambda} \sin (\theta)
$$

where $R_{\mathrm{F}}$ denotes the Fresnel reflectivity, which is the reflectivity of a perfectly flat $S i$ surface in water, $\lambda$ is the wavelength of the $\mathrm{X}$-rays, and $z$ gives the position perpendicular to the surface of the sample. The XRR experiment gives information on the laterally averaged vertical electron density profile within the layer structure. The background was determined by measuring the diffusely scattered intensity, which was subtracted from the specular reflected scattering.

Theoretical scattering curves were fitted to the experimental data using the Parratt algorithm by using the software package LSFit. ${ }^{19}$ The interfacial roughness was accounted for by applying the effectivedensity model. ${ }^{20}$ The electron density profiles used for the modeling of the polymer adsorption consisted of one layer, which was sufficient to fit the data. The dispersion values for the water subphase and the silicon wafer were taken from the literature. During the fitting procedure only the roughness of the silicon interface, the dispersion, the roughness and layer thickness of the pentablock copolymer layer were varied.

Force and Friction Measurements. The surface force and friction measurements between a silica surface and a silica spherical particle attached to the AFM cantilever were conducted in $100 \mathrm{ppm}$ pentablock copolymer solution $(1 \mathrm{mM} \mathrm{NaCl}$ at $\mathrm{pH} 9)$ and at 23,40 ${ }^{\circ} \mathrm{C}$ (below the lower critical solution temperature (LCST)), and 55 ${ }^{\circ} \mathrm{C}$ (at the LCST). The measurements were performed with a Nanoscope Multimode 8 Pico Force AFM (Bruker) in a fused silica liquid cell. A spherical silica particle (Thermo Scientific) with a diameter of about $10 \mu \mathrm{m}$ was attached to a HQ:CSC38
(MikroMasch) tipless cantilever. The actual size of each particle was measured to be within $\pm 0.1 \mu \mathrm{m}$ with a microscope using a $50 \times$ objective. The cantilever spring constant was determined using the built-in thermal tune method and was typically around $0.1 \mathrm{~N} / \mathrm{m}$. The cantilever with the attached silica particle was placed in a UV-ozone chamber (ProCleaner 220, Bioforce Nanosciences) for about $15 \mathrm{~min}$ for cleaning prior to measurements. All glassware, tubing, and the liquid cell were cleaned using $2 \%$ Hellmanex (Hellma GmbH) solution and then extensively rinsed with Milli-Q water and dried using filtered nitrogen. The deflection sensitivity was evaluated from force measurements in $\mathrm{NaCl}$ solution between the silica colloidal probe and a silica surface in the absence of the polymer. The cut silicon wafers were also cleaned by immersing them into $2 \%$ Hellmanex solution. They were then rinsed sequentially with Milli$Q$ water and ethanol before being dried using filtered nitrogen gas. The cleaning procedures and assembling were carried out in a laminar flow hood. The force curves in the $\mathrm{NaCl}$ solution and in the pentablock copolymer solution were measured at a constant piezo expansion rate of $1 \mu \mathrm{m} / \mathrm{s}$. The equilibration time after each temperature change was about $20 \mathrm{~min}$. The friction measurements were conducted with the slow scan direction disabled using a sliding speed of $4 \mu \mathrm{m} / \mathrm{s}$ and a scan length of $2 \mu \mathrm{m}$. The normal load during friction measurements was increased stepwise up to about $23 \mathrm{nN}$, with a step size of about $2.9 \mathrm{nN}$. The friction force was evaluated using the AFM Friction IT v2.5 software (Force IT, Sweden) by first calculating the difference between the friction signals for the trace and retrace directions for each scan line. More information can be found in $\operatorname{ref} 21$.

\section{RESULTS AND DISCUSSION}

Copolymer Adsorption on Silica. In a previous study, we showed that the cationic block has a high surface affinity, whereas the PIPOZ block has low affinity to silica $^{13}$ and, thus, to achieve a strong binding of the pentablock copolymer to the surface we carried out experiments at low ionic strength. The adsorption of the pentablock copolymer onto the QCM silica sensor surface led to a marked decrease in the sensor resonance frequency and an increase in dissipation, as shown in Supporting Information Figure I1. At $25^{\circ} \mathrm{C}$, it was observed that a copolymer concentration of $10 \mathrm{ppm}$ was sufficient for reaching maximum adsorption, and further increase in the copolymer concentration (Figure 2a) did not result in additional adsorption, even then the concentration was increased to $100 \mathrm{ppm}$ (Supporting Information Figure I1). This is a sign of high affinity adsorption, which is typically observed for polyelectrolytes on oppositely charged surfaces, ${ }^{22}$ and the presence of the nonionic PIPOZ blocks does not alter this generic behavior. After reaching a stable reading after each
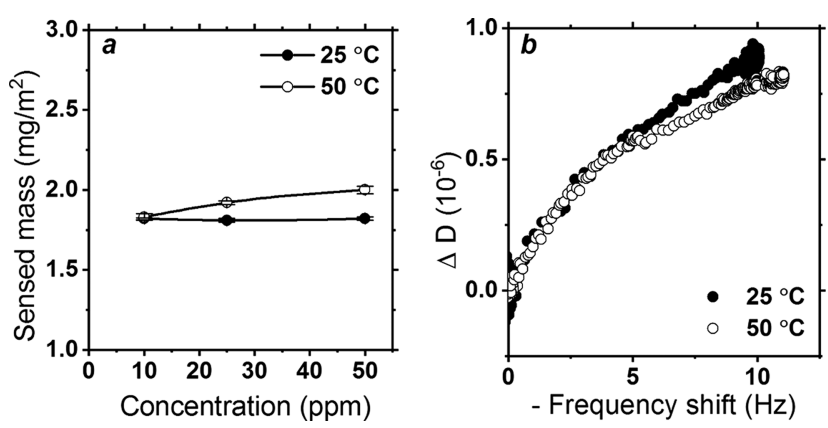

Figure 2. Sensed mass on silica calculated using the Sauerbrey model as a function of the PAMPTMA $_{15}-\mathrm{PIPOZ}_{50}-\mathrm{PAMPTMA}_{30}-$ $\mathrm{PIPOZ}_{50}-\mathrm{PAMPTMA}_{15}$ concentration at 25 and $50{ }^{\circ} \mathrm{C}$ (a). $\Delta D-\Delta f$ plots recorded during adsorption from a $10 \mathrm{ppm}$ pentablock copolymer solution (b). The data are shown for the 7 th overtone. 
increase in the pentablock copolymer concentration, buffer $\mathrm{NaCl}$ solution at $\mathrm{pH} 9$ was injected. This did not lead to any detectable copolymer desorption, which is consistent with the high affinity nature of the adsorption isotherm as discussed by Stuart et al. ${ }^{23}$

Injection of a more acidic $\mathrm{NaCl}$ solution (at $\mathrm{pH} 3$ ), which lowers the silica surface charge density, resulted in desorption as evidenced by the decrease in the magnitude of the frequency shift (see Supporting Information Figure I1). This provides further evidence for the predominant role of electrostatic forces in the adsorption process. Theoretical studies have shown that if the polyelectrolyte charge density is not too low and the salt concentration is not too high, adsorption proceeds until the charges of the adsorbed polyelectrolyte closely matches the surface charge density. ${ }^{24}$ Note, however, that when the surface has ionizable groups (silanol groups in the case of silica), adsorption of the polyelectrolyte leads to an increase in ionization of these groups. ${ }^{24,25}$

The measured frequency shifts and changes in dissipation, due to the adsorption of the pentablock copolymer, are lower than those obtained for the diblock copolymer $\mathrm{PIPOZ}_{60}-$ PAMPTMA $_{17}{ }^{13}$ a branched bottle-brush block polymer, ${ }^{26}$ and other diblock and triblock copolymers. ${ }^{27}$ This means that the pentablock copolymer layer is thin and rigid, and similar to what has been observed for polyelectrolytes with moderately high charge density. ${ }^{28}$ This rationalizes the use of the Sauerbrey model when evaluating the QCM-D data, and in $\mathrm{ref}^{29}$ it is suggested that when the change in dissipation is less than $2 \times 10^{-6}$ per $5 \mathrm{~Hz}$, then eq 1 can be used to calculate the sensed mass. The evaluated sensed mass at 25 and $50{ }^{\circ} \mathrm{C}$ are shown in Figure 2a. At $25{ }^{\circ} \mathrm{C}$, it was around $1.7 \mathrm{mg} / \mathrm{m}^{2}$ in the concentration range of $10-100 \mathrm{ppm}$ (see also Supporting Information Figure I1). We note that the sensed mass includes the mass of the polymer and any coupled solvent. The mass of the coupled solvent can be large, but it has been found to be small for thin polyelectrolyte layers. ${ }^{28}$ At $50{ }^{\circ} \mathrm{C}$, where the solvent quality for the PIPOZ blocks are reduced compared to at $25{ }^{\circ} \mathrm{C}$, the sensed mass increased with the increasing copolymer concentration from $1.8 \mathrm{mg} / \mathrm{m}^{2}$ at $10 \mathrm{ppm}$ to 2.0 $\mathrm{mg} / \mathrm{m}^{2}$ at $50 \mathrm{ppm}$. These findings are consistent with the general trend for other copolymers ${ }^{13,30}$ where an increase of the sensed mass with decreasing solvent quality has been observed.

To gain additional information on the adsorbed copolymer layer $\Delta D-\Delta f$ plots evaluated at 25 and $50{ }^{\circ} \mathrm{C}$ are presented in Figure $2 \mathrm{~b}$. At both temperatures the dissipation change is increasing sublinearly with the frequency change. This is a sign of stiffening of the adsorbed copolymer layer, as previously observed for diblock copolymers and bottle-brush copolymers. ${ }^{13,26}$ This is due to the increased interactions between the polymer chains. We note that for any given frequency shift, larger than $5 \mathrm{~Hz}$ in magnitude, the dissipation shift is lower at higher temperatures. This is an effect of the worsening of the solvency conditions for the PIPOZ blocks, leading to partial dehydration and more favorable segment-segment interactions. In contrast, the linear dependence between the frequency and dissipation shifts is, up to about $5 \mathrm{~Hz}$, similar at both temperatures, i.e., when the adsorbed layer consists of separated, and thus weakly interacting polymer chains.

X-ray Reflectivity. The XRR curves along with the fits are shown in Figure 3a. The electron density profiles are given in Figure $3 b$.
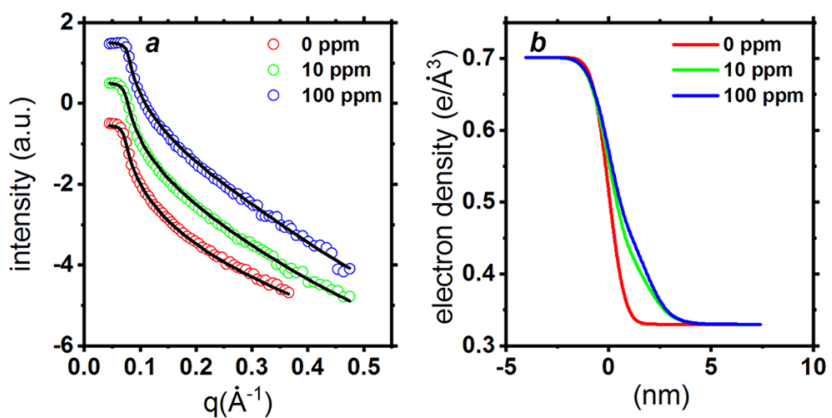

Figure 3. (a) X-ray reflectivity curves of the adsorbed PAMPTMA ${ }_{15}$ $\mathrm{PIPOZ}_{50}-\mathrm{PAMPTMA}_{30}-\mathrm{PIPOZ}_{50}-\mathrm{PAMPTMA}_{15}$ polymer layer at a silicon wafer surface. The copolymer concentration was 10 and 100 ppm, respectively. For comparison, a solution without a copolymer was used $(0 \mathrm{ppm})$. The experiments were performed at $22^{\circ} \mathrm{C}$. The curves are shifted vertically for clarity. Black lines denote the fits to the data. (b) Electron density profiles obtained from the data fitting. The profiles clearly show the formation of a layer with a nondistinct boarder to the solution, with the decreasing polymer mass away from the silica surface.

The data show no pronounced oscillation, which suggests the formation of nondistinct layer-solution interface with high intrinsic roughness. By comparing the XRR curves from the interface with no adsorbed polymer $(0 \mathrm{ppm})$ to the data in the presence of the polymer, we note a stronger decay of the reflected intensity in the presence of the adsorbed polymer layer. This indicates a significantly rougher layer system. Fitting is achieved by using a model with one layer in the presence of the polymer and without any layer for the $\mathrm{NaCl}$ solution. The overall parameters resulting from the fitting are summarized in Table 1.

The silicon wafer has a roughness that varies between 0.62 and $0.77 \mathrm{~nm}$, which is reasonable considering that the roughness of the silicon wafer can vary depending on the manufacturer and treatment. In particular, the use of the alkaline Hellmanex solution for cleaning can induce changes in the surface roughness. The thickness of the adsorbed copolymer layer was determined to be $2 \pm 0.2 \mathrm{~nm}$. This is in good accordance with the observations from QCM-D measurements, where no significant difference of the adsorbed mass could be detected for the two concentrations. The thickness can also be estimated from the QCM-D data, and here, we obtain a layer thickness of $1.7 \mathrm{~nm}$ (assuming a density of the layer of $1 \mathrm{~g} / \mathrm{cm}^{3}$ ). The XRR data show that the roughness of the adsorbed films is around $0.9 \mathrm{~nm}$, indicating the formation of a nondistinct polymer-solution interface as expected.

The electron density profiles reported in Figure $3 \mathrm{~b}$ provide information on the layer structure. The layer shows a mass gradient from the interface into bulk solution, where most adsorbed mass is found in close proximity to the silica interface. We note that the fitting predicts a layer thickness of 2 $\mathrm{nm}$, but neither QCM-D nor XRR is sensitive to the presence of a dilute tail and a loop region, and it is reasonable to suggest that some tails and loops extend further from the surface. Indeed, this is observed in the AFM surface force study, which is sensitive to the dilute polymer region, but does not provide information on the layer thickness.

Surface Forces. The forces acting on approach between a silica particle and a silica surface across a $1 \mathrm{mM} \mathrm{NaCl}$ solution at $\mathrm{pH} 9$ containing $100 \mathrm{ppm}$ of the pentablock copolymer are 
Table 1. Fitting Parameters for the XRR Curves

$\begin{array}{cccc}\text { copolymer concentration }(\mathrm{ppm}) & \mathrm{Si} \text { interface roughness }(\mathrm{nm}) & \text { copolymer layer dispersion } & \text { copolymer layer roughness }(\mathrm{nm}) \\ 0 & 0.62 \pm 0.05 & \text { copolymer layer thickness }(\mathrm{nm}) \\ 10 & 0.77 \pm 0.05 & 0.96 \pm 0.01 & 0.96 \pm 0.05 \\ 100 & 0.77 \pm 0.05 & 0.95 \pm 0.01 & 0.94 \pm 0.05\end{array}$

shown in Figure 4. The force curve has two distinct regions. The long-range force is due to a double-layer force. A

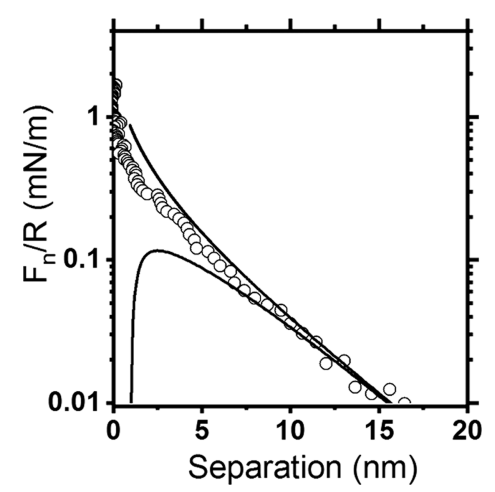

Figure 4. Typical force curve normalized by the colloidal probe radius measured on approach between a silica sphere and a silica surface across a $1 \mathrm{mM} \mathrm{NaCl}$ solution containing $100 \mathrm{ppm}$ PAMPTMA $_{15}-$ $\mathrm{PIPOZ}_{50}-\mathrm{PAMPTMA}_{30}-\mathrm{PIPOZ}_{50}-\mathrm{PAMPTMA}_{15}$ at $\mathrm{pH} 9$ and a temperature of $23{ }^{\circ} \mathrm{C}$. The solid lines are calculated DLVO forces using constant surface charge density (upper line) and constant surface potential (lower line) boundary conditions.

Derjaguin, Landau, Vervey, and Overbeek (DLVO) model, ${ }^{31,32}$ using solutions to the nonlinear Poisson-Boltzmann equation and a nonretarded Hamaker constant of $6.3 \times 10^{-21} \mathrm{~J},{ }^{33}$ describes the long-range force satisfactorily. The DLVO model based on constant surface potential conditions predicts a slightly lower force at short separation below $10 \mathrm{~nm}$ than the measured force, whereas the DLVO model based on constant surface charge density conditions predicts slightly higher force values. This suggests charge regulation leading to a decrease in the surface charge density and increase in the surface potential with decreasing separation. The fit shown in Figure 4 provides a Debye length of $4.2 \mathrm{~nm}$, corresponding to a $1: 1$ electrolyte concentration of about $5 \mathrm{mM}$, which is slightly higher than expected, even considering that some $\mathrm{NaOH}$ and $\mathrm{HCl}$ were added to the $1 \mathrm{mM} \mathrm{NaCl}$ solution to adjust the $\mathrm{pH}$. Thus, it seems likely that the cationic pentablock copolymer contributes to the Debye length. The magnitude of the surface potential at large separations was found to be about $14 \mathrm{mV}$, and the corresponding surface charge density is $7 \mathrm{mC} / \mathrm{m}^{2}$. At distances less than $3 \mathrm{~nm}$ the slope of the force curve becomes steeper, suggesting the predominance of the steric forces that are not captured within the DLVO model.

The forces measured on approach and separation across a 100 ppm pentablock copolymer solution ( $\mathrm{pH}$ 9) at different temperatures are shown in Figure 5. A repulsive double-layer force is observed at all temperatures below the phase transition temperature, and we concluded that there is no evidence for long polymer loops or tails, and we estimate the range of the steric force to be about $3 \mathrm{~nm}$ from hard wall contact. This contrasts to what was reported for a poly $(\mathrm{N}$-isopropylacrylamide) (PNIPAM)-PAMPTMA diblock copolymer (range of steric force around $95 \mathrm{~nm}^{27}$ ) and for a methoxy poly (ethylene glycol)-PNIPAM-PAMPTMA triblock copolymer (range of
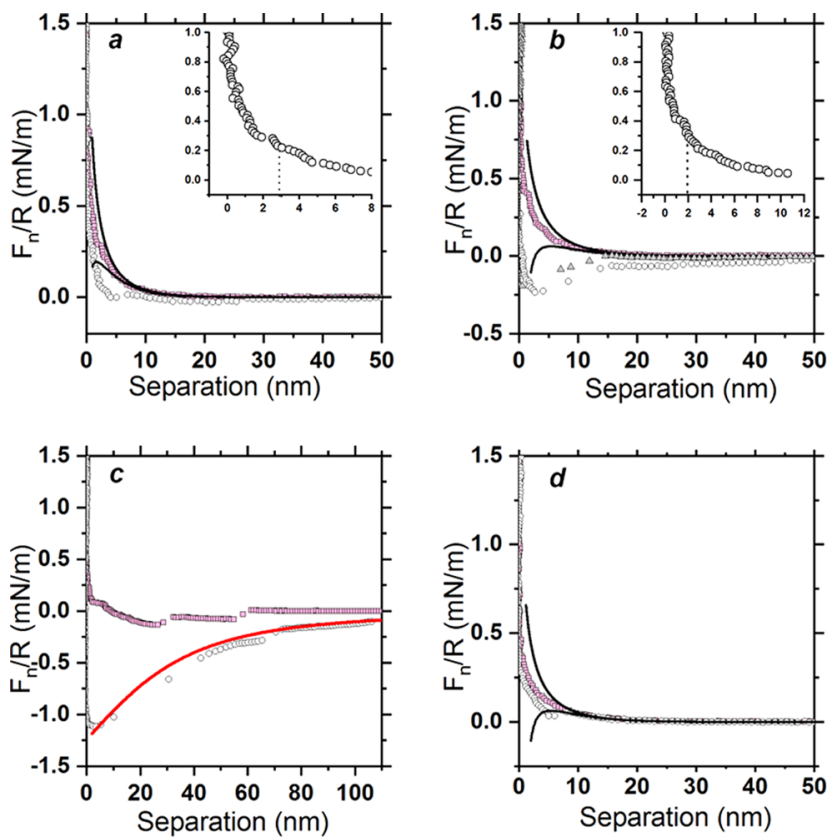

Figure 5. Force normalized by the colloidal probe radius measured on approach (open pink squares) and retraction (open circles) at different temperatures of $23{ }^{\circ} \mathrm{C}(\mathrm{a}), 40^{\circ} \mathrm{C}(\mathrm{b}), 55^{\circ} \mathrm{C}$ (c), and $28{ }^{\circ} \mathrm{C}$ on cooling (d). The interactions are probed across a $1 \mathrm{mM} \mathrm{NaCl}$ solution containing $100 \mathrm{ppm} \mathrm{PAMPTMA}_{15}-\mathrm{PIPOZ}_{50}-\mathrm{PAMPT}$ $\mathrm{MA}_{30}-\mathrm{PIPOZ}_{50}-\mathrm{PAMPTMA}_{15}$ at $\mathrm{pH}$ 9. The temperature $55{ }^{\circ} \mathrm{C}$ is at the LCST. The black solid lines are the DLVO fits. The axis labels in the insets are the same as in the main figure. The filled gray triangles in (b) show the retraction curve on cooling at $40{ }^{\circ} \mathrm{C}$. The red solid line in (c) represents a capillary force calculated using in the constant condensate volume model.

steric force around $10 \mathrm{~nm}^{27}$ ). We note that in the work reported in ref, ${ }^{27}$ the double-layer force and the electrostatic polyelectrolyte-surface attraction was slightly more screened than in our case (10 $\mathrm{mM}$ salt concentration). It has previously been shown that the addition of salt that reduces the electrostatic surface affinity leads to a strongly increased range of the steric force between polyelectrolyte-coated surfaces, ${ }^{34}$ but it is unlikely that such an effect rationalizes the difference between the data reported here and in ref. ${ }^{27}$ Our data is more similar to that reported for a $\mathrm{PIPOZ}_{60}-$ PAMPTMA $_{17}$ diblock copolymer, where a steric force became predominant at separations below $5 \mathrm{~nm},{ }^{12,14}$ which still is larger than the $3 \mathrm{~nm}$ found for the pentablock copolymer in this study. This reflects that the tails formed by the $\mathrm{PIPOZ}_{60}-$ PAMPTMA $_{17}$ diblock copolymer extends further from the hard wall contact than the loops formed by the PAMPTMA ${ }_{15}$ $\mathrm{PIPOZ}_{50}-\mathrm{PAMPTMA}_{30}-\mathrm{PIPOZ}_{50}-\mathrm{PAMPTMA}_{15}$ pentablock copolymer. This is consistent with the XRR and QCM-D results proposing a thin and stiff pentablock copolymer layer on the silica surface.

A small kink at distances of around $2-3 \mathrm{~nm}$ can be seen in the force curve on approach, see the insets in Figure 5a,b, suggesting a pressure induced change in the polymer 
conformation. We assign this to the collapse of the extended loops formed by the PIPOZ blocks. The forces measured on approach at $55{ }^{\circ} \mathrm{C}$ are of a much longer range, appearing already at a distance of around $60 \mathrm{~nm}$. We note that this force is attractive and several small steps can be seen in the force curve. This temperature is at the LCST and the deposition of aggregates is predicted to initiate just below the LCST. ${ }^{35-37}$ Our data is consistent with this, and thus interpreted as being due to the rearrangement of copolymer aggregates formed on the silica surfaces, as previously reported for a PIPOZPAMPTMA diblock copolymer. ${ }^{13}$

On separation, a very weak attractive force is observed at 23 ${ }^{\circ} \mathrm{C}$, suggesting a weak bridging attraction. This attraction is amplified at $40{ }^{\circ} \mathrm{C}$ as the solvent quality of the PIPOZ blocks is reduced. At both temperatures the attraction persists to rather large distances, providing evidence for stretching of polymer chains attached to both surfaces during separation.

At $55^{\circ} \mathrm{C}$, the attraction is significantly larger and extends to more than $100 \mathrm{~nm}$, which is a too large range to be explained by bridging. We conclude that a capillary condensate of a polymer-rich phase has formed in the gap between the two interacting surfaces, as also has been observed in other studies. $^{12,38}$ With the AFM technique, the formation of a capillary condensate is only inferred from the force measurements. However, with the use of a surface force apparatus the change in the refractive index due to the formation of a capillary condensate is readily detected also from the shape of the interference fringes. Indeed, this has been reported for a phase separating surfactant system. ${ }^{39}$

A fundamental description of capillary condensate formation, resulting in a polymer-rich and polymer-poor phase, is given in a theoretical work ${ }^{40}$ employing density functional theory to elucidate surface forces in polymer solutions. Furthermore, Butt and Kappl have provided a quantitative description of the capillary forces, employing continuum theory with an AFM-based experimental verification. ${ }^{41}$ The red solid line in Figure $5 \mathrm{c}$ is a fit of capillary forces to the experimental data. Here, we considered the case with a constant capillary volume (the full equilibrium case that allows variation in the capillary volume with separation did not agree well with the data), as described by eq 4

$$
\frac{F}{R}=4 \pi\left(\gamma_{\mathrm{sc}}-\gamma_{\mathrm{sb}}\right)\left(1-\frac{1}{\sqrt{1+\frac{R_{\mathrm{k}}^{2}}{D^{2}}}}\right)
$$

where $\gamma$ is the interfacial tension and the subscripts $s, c$, and $b$ stands for surface, capillary condensate, and bulk, respectively. $R_{\mathrm{k}}$ is the Kelvin radius of the capillary condensate and $D$ is the separation distance.

The Kelvin radius was found to be about $42 \pm 2 \mathrm{~nm}$ at 55 ${ }^{\circ} \mathrm{C}$, and the interfacial tension difference was about $0.1 \pm 0.01$ $\mathrm{mN} / \mathrm{m}$, as calculated from 10 different force curves. The obtained interfacial tension difference is less than $0.26 \mathrm{mN} / \mathrm{m}$ found for the PIPOZ-PAMPTMA diblock copolymer, ${ }^{12}$ and slightly larger than found for a microemulsion system, where a value of less than $0.05 \mathrm{mN} / \mathrm{m}$ was reported. ${ }^{38}$

We note that long-lived trapped states are common when polyelectrolytes are adsorbed to oppositely charged surfaces due to their strong surface affinity. In particular, for a PIPOZPAMPTMA diblock copolymer it has been reported that adsorption readily increases when the temperature is increased, but desorption due to a subsequent temperature decrease is slow. ${ }^{12}$ We notice long-lived trapped states also for the pentablock copolymer investigated here. The capillary condensate that was present at $55{ }^{\circ} \mathrm{C}$ readily disappears as the temperature is decreased back to $40{ }^{\circ} \mathrm{C}$, but some of the additional polymers that have adsorbed directly to the surface appears to remain, leading to reduced adhesion. Furthermore, the adhesion found at $28{ }^{\circ} \mathrm{C}$ on cooling is lower than that found at $23{ }^{\circ} \mathrm{C}$ prior to heating, as shown in Figure 6. We note

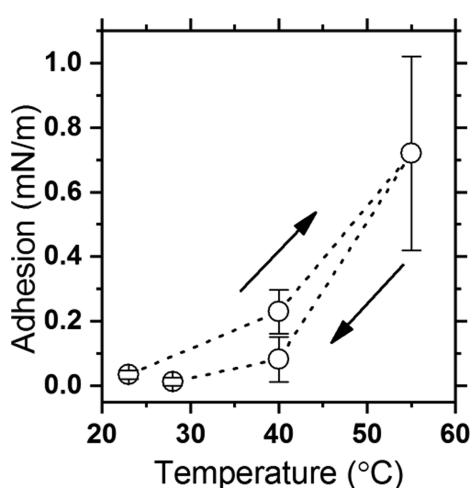

Figure 6. Adhesion force as a function of temperature. The dotted lines are guides to the eye and the arrows show the direction of the experiment where the solution is first heated and then cooled.

that the variation in the measured adhesion force in the presence of a capillary condensate at $55{ }^{\circ} \mathrm{C}$ is significantly larger compared to lower temperatures when no capillary condensate is present.

Friction Forces. The friction force is a measure of the energy dissipation during sliding, and any mechanism that provides energy dissipation will contribute to the friction force. There are many such mechanisms that may act between polymer layers, as discussed in a recent review article and references therein. ${ }^{42}$ It is understood that the friction increases with the increasing degree of chain interpenetration between the opposing surface layers, and modeling has shown that chain interpenetration increases with worsening solvent conditions. ${ }^{14}$ Disruption and reformation of attractive segment-segment contacts and bridging chains also provide important energy dissipation mechanisms.

The friction force as a function of normal load is shown in Figure 7. The very low friction force expected at low loads due to the presence of a long-range double-layer force is not captured. This is due to the fact that already at an applied load of $3 \mathrm{nN}(F / R \approx 0.6 \mathrm{mN} / \mathrm{m})$ a steric force predominates (see inset Figure $5 \mathrm{a}, \mathrm{b})$. At $23{ }^{\circ} \mathrm{C}$, the polymer layer becomes strongly compressed and the hard wall repulsion is encountered at normal loads at and above $7 \mathrm{nN}$, corresponding to $F / R=1.4 \mathrm{mN} / \mathrm{m}$ (see Figure $5 \mathrm{a}$ ). In our case, the standard Amontons' rule does not hold, but the data were fitted to Amontons' rule modified by considering the effect of surface adhesion

$$
F_{\mathrm{f}}=F_{\mathrm{adh}}+\mu F_{\mathrm{n}}
$$

here $F_{\mathrm{f}}$ is the friction force, $F_{\mathrm{adh}}$ is the adhesion force, $F_{\mathrm{n}}$ is the normal force, and $\mu$ is the friction coefficient.

We note that the adhesion force during sliding may differ from the adhesion force determined during normal force measurements, ${ }^{43}$ but in our case good fits were obtained using adhesion force values determined from the force measure- 

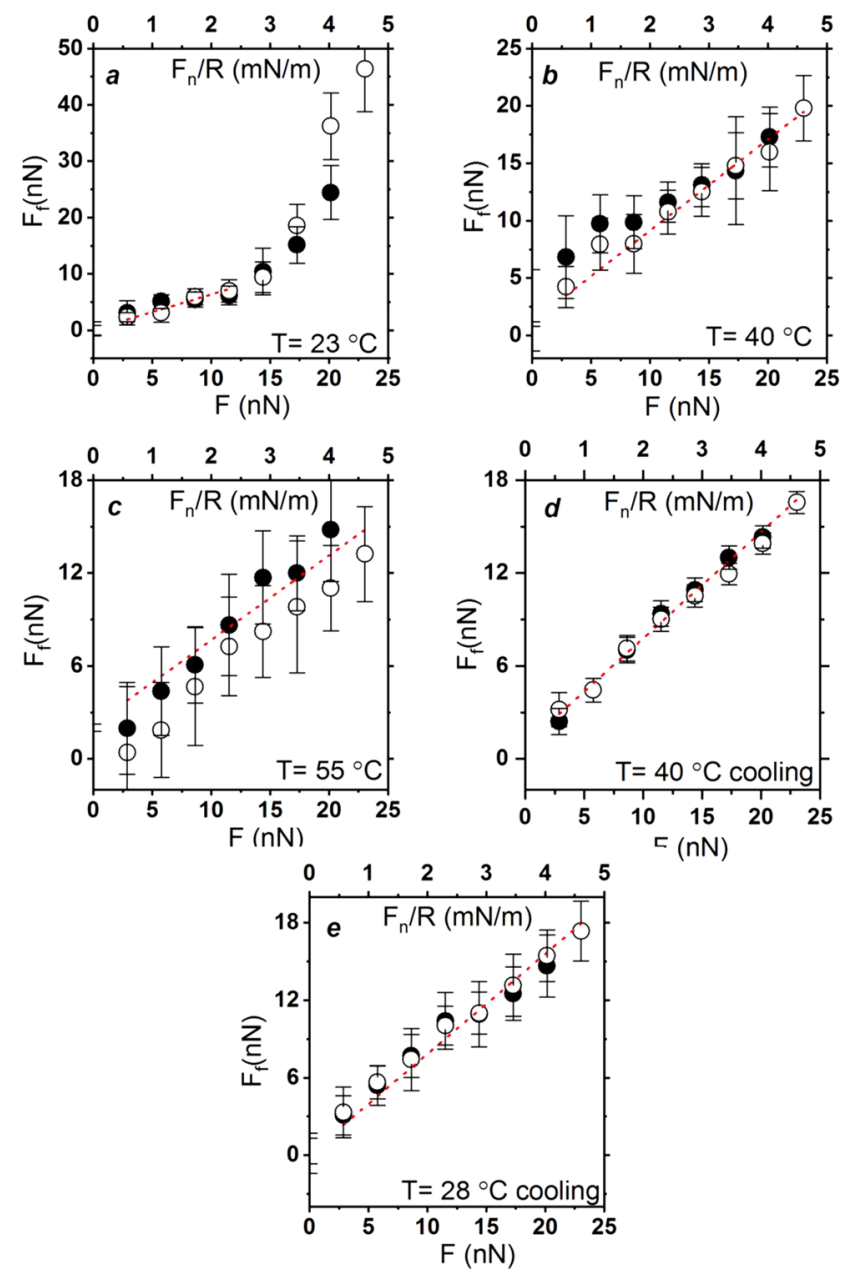

Figure 7. Friction force as a function of applied normal load as measured between a silica sphere and a silica surface across a $1 \mathrm{mM}$ $\mathrm{NaCl}$ solution at $\mathrm{pH} 9$ containing $100 \mathrm{ppm}$ of the $\mathrm{PAMPTMA}_{15}$ $\mathrm{PIPOZ}_{50}-\mathrm{PAMPTMA}_{30}-\mathrm{PIPOZ}_{50}-\mathrm{PAMPTMA}_{15}$ pentablock copolymer. The measurements were performed as the temperature was first increased stepwise from 23 to $40{ }^{\circ} \mathrm{C}$ and to $55^{\circ} \mathrm{C}(\mathrm{a}-\mathrm{c})$ and subsequently cooled to 40 and $28^{\circ} \mathrm{C}(\mathrm{d}, \mathrm{e})$. The filled spheres show data obtained when increasing the load, whereas the open circles show data obtained during the subsequent decrease in load. The red dotted lines are the fits obtained by using the modified Amontons' rule (eq 5).

ments in the absence of a capillary condensate, as reported in Figure 6. At $23{ }^{\circ} \mathrm{C}$, there is a good fit up to a normal load of 12 $\mathrm{nN}$, above which the friction force increases strongly. This is a sign of wear of the adsorbed layer as the polymers are dragged along the surface due to the combined action of load and shear, which results in energy dissipation. The friction coefficient obtained from the fitting is $0.62 \pm 0.02$, which is slightly higher than that that obtained for a PNIPAAM-PAMPTMA diblock copolymer at $25{ }^{\circ} \mathrm{C}$. ${ }^{44}$ Thus, no significant lowering of friction was observed for the loop-dominated pentablock layer compared to the tail-dominated diblock copolymer layer. This is most likely due to the relatively short length of the PNIPAAM loops, resulting in only short-range steric forces. In other cases, friction reduction has been noted for loopdominated copolymer structures. ${ }^{10,11}$

At $40{ }^{\circ} \mathrm{C}$, the layer is more resistant towards wear due to the worsening of the solvent conditions for the PIPOZ blocks. In this case, the modified Amontons' rule described the results well over the whole range of applied loads. Thus, we see no evidence for wear of the adsorbed layer at this temperature. A similar effect, with the decreasing wear as the solvency conditions was becoming worse, has previously been reported for surfaces coated with methylcellulose. ${ }^{45}$ The friction coefficient was slightly higher at $40{ }^{\circ} \mathrm{C}, 0.69 \pm 0.02$, than at the lower temperature. This is consistent with previous measurements using preadsorbed $\mathrm{PIPOZ}_{60}-\mathrm{PAMPTMA}_{17}$ diblock copolymers ${ }^{4}$ and the same diblock copolymer in solution. $^{12}$

As the temperature was further increased up to the phase transition temperature at $55{ }^{\circ} \mathrm{C}$, the modified Amontons' rule does not accurately fit the data when the measured adhesion force reported in Figure 6 is used, but a higher adhesion force is required (red line in Figure $7 \mathrm{c}$ ). This is not surprising considering that we now have a capillary condensate present between the surfaces, and the size of the condensate may change during the time it takes to perform the friction measurements. The evaluated friction coefficient using eq 5 was 0.55 , lower than in the absence of the capillary condensate. This was unexpected considering that during sliding the capillary condensate has to move across the surface, which should cause additional energy dissipation. It may suggest that the additional adsorption that occurs at the higher temperature results in less chain interpenetration and that this lowers the friction, as observed for the effective friction coefficient for PIPOZ $_{60}-$ PAMPTMA $_{17}$ adsorbed on the silica surfaces. ${ }^{12}$ Furthermore, a marked hysteresis, with a higher friction on loading than on unloading, is observed at $55^{\circ} \mathrm{C}$. This could be due to additional polymer adsorption or due to the propensity of PIPOZ chains to crystallize at high temperatures.

When the temperature was subsequently lowered from 55 to 40 and $28{ }^{\circ} \mathrm{C}$, respectively, we observe an effect of long-lived trapped states. The additional adsorption that occurred at higher temperatures resulted in (i) slightly lower friction forces than observed at similar temperatures on heating, which correlates with the lower adhesion force (Figure 6), and (ii) no evidence for shear induced wear even at $28{ }^{\circ} \mathrm{C}$. On cooling, there was no measurable hysteresis in the friction force measured on loading and unloading, so this feature was only observed in the presence of the capillary condensate at $55^{\circ} \mathrm{C}$.

\section{CONCLUSIONS}

We have elucidated the adsorption of a pentablock copolymer, PAMPTMA $_{15}-\mathrm{PIPOZ}_{50}-\mathrm{PAMPTMA}_{30}-\mathrm{PIPOZ}_{50}-\mathrm{PAMPT}$ $\mathrm{MA}_{15}$, on silica surfaces and the effects on the surface and friction forces as a function of temperature up to the phase transition temperature. The copolymer layer is thin and rigid, as concluded from XRR, QCM-D, and surface force measurements. XRR data provide a layer thickness of $2 \mathrm{~nm}$, which is consistent with the QCM-D data, and the surface force data suggest that some loops or tails extend about $3 \mathrm{~nm}$ from hard wall contact, less than for the corresponding diblock copolymer. $^{12,14}$

At a temperature of $50{ }^{\circ} \mathrm{C}$ the sensed mass registered by QCM-D is higher than at $23{ }^{\circ} \mathrm{C}$ due to worsening of the solvent conditions, in agreement with general trends for polymers with a LCST. ${ }^{13,30}$ At a temperature of $55{ }^{\circ} \mathrm{C}$, corresponding to the cloud point temperature, a strong attraction due to the formation of a capillary condensate of a polymer-rich phase was observed, as was also the case for the $\mathrm{PIPOZ}_{60}-\mathrm{PAMPTMA}_{17}$ diblock copolymer at the corresponding cloud point. ${ }^{12,14}$ Fitting of a capillary force model, 
assuming the constant capillary volume, to the force data at 55 ${ }^{\circ} \mathrm{C}$ gave a Kelvin radius of $42 \pm 2 \mathrm{~nm}$ and an interfacial tension difference of $0.1 \pm 0.01 \mathrm{mN} / \mathrm{m}$, which was smaller than the $0.26 \mathrm{mN} / \mathrm{m}$ found for the $\mathrm{PIPOZ}_{60}-\mathrm{PAMPTMA}_{17}$ diblock copolymer. $^{12}$

At temperatures below the cloud point, the Amontons' modified rule was found to adequately describe the friction force versus load data using measured adhesion forces. However, in the presence of the capillary condensate at 55 ${ }^{\circ} \mathrm{C}$ a higher adhesion force was observed during sliding compared to during force measurements. This could be due to a growth of the capillary condensate with time. At $23{ }^{\circ} \mathrm{C}$, the wear resistance of the layer was relatively low, and the friction force increased significantly above a load of $15 \mathrm{nN}$ as the polymer chains were dragged along the surface. No similar wear was observed at higher temperatures due to increased adsorption and more favorable segment-segment interactions. Unexpectedly, the friction coefficient was found to be lower in the presence of the capillary condensate (at $55{ }^{\circ} \mathrm{C}$ ) than at lower temperatures. We propose that this is due to increased adsorption that reduces chain interpenetration and possibly due to the propensity of PIPOZ chains to crystallize from water at high temperatures. Long-lived trapped states were noticed, and gave rise to lower friction and lower adhesion at a given temperature on subsequent cooling than observed originally at that temperature. This is attributed to no or slow desorption of additional polymers adsorbed at high temperatures. Low friction forces, as observed for other loopforming polymers ${ }^{10,11}$ was not detected in this investigation. Presumably, the PIPOZ blocks were too short to favor extended loops, as also suggested by the XRR data.

\section{ASSOCIATED CONTENT}

\section{S Supporting Information}

The Supporting Information is available free of charge on the ACS Publications website at DOI: 10.1021/acs.langmuir.8b03729.

Adsorption of the pentablock copolymer onto the QCM silica sensor at $25^{\circ} \mathrm{C}(\mathrm{PDF})$

\section{AUTHOR INFORMATION}

\section{Corresponding Author}

*E-mail: illia@kth.se.

\section{ORCID $\odot$}

Illia Dobryden: 0000-0001-6877-9282

Françoise M. Winnik: 0000-0001-5844-6687

\section{Notes}

The authors declare no competing financial interest.

\section{ACKNOWLEDGMENTS}

This work is supported by the Swedish Research Council, VR, contract number [2015-05080] and F.M.W. acknowledges grants from the Natural Science and Engineering Research Council of Canada and of MEXT Japan (World Premier Initiative). M.C.R. acknowledges funding through the National Science Foundation under award NSF OISE 1358179.

\section{REFERENCES}

(1) Fuentes, I.; Blanco-Fernandez, B.; Alvarado, N.; Leiva, Á.; Radić, D.; Alvarez-Lorenzo, C.; Concheiro, A. Encapsulation of Antioxidant Gallate Derivatives in Biocompatible Poly $(\varepsilon$-caprolactone)-b-Plur-
onic-b-Poly ( $\varepsilon$-caprolactone) Micelles. Langmuir 2016, 32, 33313339.

(2) Uz, M.; Mallapragada, S. K.; Altinkaya, S. A. Responsive pentablock copolymers for siRNA delivery. RSC $A d v$. 2015, 5, 43515-43527.

(3) Dai, Y.; Chen, X.; Zhang, X. Recent advances in stimuliresponsive polymeric micelles via click chemistry. Polym. Chem. 2018, 34-44.

(4) Kim, J. K.; Yang, S. Y.; Lee, Y.; Kim, Y. Functional nanomaterials based on block copolymer self-assembly. Prog. Polym. Sci. 2010, 35, $1325-1349$

(5) Gaitzsch, J.; Huang, X.; Voit, B. Engineering Functional Polymer Capsules toward Smart Nanoreactors. Chem. Rev. 2016, 116, 10531093.

(6) Contreras-García, A.; Alvarez-Lorenzo, C.; Taboada, C.; Concheiro, A.; Bucio, E. Stimuli-responsive networks grafted onto polypropylene for the sustained delivery of NSAIDs. Acta Biomater. 2011, 7, 996-1008.

(7) Eeckman, F.; Moës, A. J.; Amighi, K. Evaluation of a new controlled-drug delivery concept based on the use of thermoresponsive polymers. Int. J. Pharm. 2002, 241, 113-125.

(8) Jacob, K. Entropic interactions: neutral and end-functionalized chains in confined geometries. J. Phys.: Condens. Matter 2000, 12, A19.

(9) Benetti, E. M.; Divandari, M.; et al. Loops and Cycles at Surfaces: The Unique Properties of Topological Polymer Brushes. Chem. - Eur. J. 2017, 23, 12433-12442.

(10) Banquy, X.; Burdyńska, J.; Lee, D. W.; Matyjaszewski, K.; Israelachvili, J. Bioinspired Bottle-Brush Polymer Exhibits Low Friction and Amontons-like Behavior. J. Am. Chem. Soc. 2014, 136, 6199-6202.

(11) Kang, T.; Banquy, X.; Heo, J.; Lim, C.; Lynd, N. A.; Lundberg, P.; Oh, D. X.; Lee, H.-K.; Hong, Y.-K.; Hwang, D. S.; Waite, J. H.; Israelachvili, J. N.; Hawker, C. J. Mussel-Inspired Anchoring of Polymer Loops That Provide Superior Surface Lubrication and Antifouling Properties. ACS Nano 2016, 10, 930-937.

(12) An, J.; Liu, X.; Dedinaite, A.; Korchagina, E.; Winnik, F. M.; Claesson, P. M. Effect of solvent quality and chain density on normal and frictional forces between electrostatically anchored thermoresponsive diblock copolymer layers. J. Colloid Interface Sci. 2017, 487, $88-96$.

(13) An, J.; Dèdinaitè, A.; Winnik, F. M.; Qiu, X. P.; Claesson, P. M. Temperature-dependent adsorption and adsorption hysteresis of a thermoresponsive diblock copolymer. Langmuir 2014, 30, 43334341.

(14) An, J.; Liu, X.; Linse, P.; Dedinaite, A.; Winnik, F. M.; Claesson, P. M. Tethered Poly(2-isopropyl-2-oxazoline) Chains: Temperature Effects on Layer Structure and Interactions Probed by AFM Experiments and Modeling. Langmuir 2015, 31, 3039-3048.

(15) Radzevicius, P.; Steponaviciute, M.; Krivorotova, T.; Makuska, R. Double thermoresponsive pentablock copolymers: synthesis by one-pot RAFT polymerization and self-assembly in aqueous solutions. Polym. Chem. 2017, 8, 7217-7228.

(16) Chen, T.; Lu, Y.; Chen, T.; Zhang, X.; Du, B. Adsorption of PNIPAmx-PEO20-PPO70-PEO20-PNIPAmx pentablock terpolymer on gold surfaces: effects of concentration, temperature, block length, and surface properties. Phys. Chem. Chem. Phys. 2014, 16, 5536-5544.

(17) Lu, Y.; Zhang, X.; Fan, Z.; Du, B. Adsorption of PNIPAm110PEO100-PPO65-PEO100-PNIPAm110 pentablock terpolymer on hydrophobic gold. Polymer 2012, 53, 3791-3801.

(18) Sauerbrey, G. Verwendung von Schwingquarzen zur Wägung dünner Schichten und zur Mikrowägung. Z. Phys. 1959, 155, 206222.

(19) Parratt, L. G. Surface Studies of Solids by Total Reflection of XRays. Phys. Rev. 1954, 95, 359-369.

(20) Tolan, M. X-Ray Scattering from Soft-Matter Thin Films: Materials Science and Basic Research; Springer-Verlag: Berlin Heidelberg, 1999. 
(21) Pettersson, T.; Dedinaite, A. Normal and friction forces between mucin and mucin-chitosan layers in absence and presence of SDS. J. Colloid Interface Sci. 2008, 324, 246-256.

(22) Rojas, O. J.; Ernstsson, M.; Neuman, R. D.; Claesson, P. M. Effect of Polyelectrolyte Charge Density on the Adsorption and Desorption Behavior on Mica. Langmuir 2002, 18, 1604-1612.

(23) Stuart, M. A. C.; Fleer, G. J. Adsorbed polymer layers in nonequilibrium situations. Annu. Rev. Mater. Sci. 1996, 26, 463-500.

(24) Shubin, V.; Linse, P. Self-consistent-field modeling of polyelectrolyte adsorption on charge-regulating surfaces. Macromolecules 1997, 30, 5944-5952.

(25) Lundin, M.; Macakova, L.; Dedinaite, A.; Claesson, P. Interactions between Chitosan and SDS at a Low-Charged Silica Substrate Compared to Interactions in the BulkThe Effect of Ionic Strength. Langmuir 2008, 24, 3814-3827.

(26) Liu, X.; Dedinaite, A.; Rutland, M.; Thormann, E.; Visnevskij, C.; Makuska, R.; Claesson, P. M. Electrostatically anchored branched brush layers. Langmuir 2012, 28, 15537-15547.

(27) Zajforoushan Moghaddam, S.; Zhu, K.; Nyström, B.; Thormann, E. Thermo-responsive diblock and triblock cationic copolymers at the silica/aqueous interface: A QCM-D and AFM study. J. Colloid Interface Sci. 2017, 505, 546-555.

(28) Plunkett, M. A.; Claesson, P. M.; Ernstsson, M.; Rutland, M. W. Comparison of the adsorption of different charge density polyelectrolytes: A quartz crystal microbalance and X-ray photoelectron spectroscopy study. Langmuir 2003, 19, 4673-4681.

(29) Reviakine, I.; Johannsmann, D.; Richter, R. P. Hearing What You Cannot See and Visualizing What You Hear: Interpreting Quartz Crystal Microbalance Data from Solvated Interfaces. Anal. Chem. 2011, 83, 8838-8848.

(30) Claesson, P. M.; Gölander, C.-G. Direct measurements of steric interactions between mica surfaces covered with electrostatically bound low-molecular-weight polyethylene oxide. J. Colloid Interface Sci. 1987, 117, 366-374.

(31) Derjaguin, B.; Landau, L. Theory of the stability of strongly charged lyophobic sols and of the adhesion of strongly charged particles in solutions of electrolytes. Acta Physicochim. URSS 1941, 14, 633-662.

(32) Overbeek, J.T.G.; Verwey, E. J. W. Theory of the Stability of Lyophobic Colloids; Elsevier Pub. Co.: New York, 1948.

(33) Bergström, L. Hamaker constants of inorganic materials. Adv. Colloid Interface Sci. 1997, 70, 125-169.

(34) Dahlgren, M. A. G.; Waltermo, A.; Blomberg, E.; Claesson, P. M.; Sjoestroem, L.; Aakesson, T.; Joensson, B. Salt effects on the interaction between adsorbed cationic polyelectrolyte layers: theory and experiment. J. Phys. Chem. 1993, 97, 11769-11775.

(35) Kujawa, P.; Aseyev, V.; Tenhu, H.; Winnik, F. M. TemperatureSensitive Properties of Poly(N-isopropylacrylamide) Mesoglobules Formed in Dilute Aqueous Solutions Heated above Their Demixing Point. Macromolecules 2006, 39, 7686-7693.

(36) Katsumoto, Y.; Tsuchiizu, A.; Qiu, X.; Winnik, F. M. Dissecting the Mechanism of the Heat-Induced Phase Separation and Crystallization of Poly(2-isopropyl-2-oxazoline) in Water through Vibrational Spectroscopy and Molecular Orbital Calculations. Macromolecules 2012, 45, 3531-3541.

(37) Linse, P.; Wennerström, H. Adsorption versus aggregation. Particles and surface of the same material. Soft Matter 2012, 8, 24862493.

(38) Petrov, P.; Olsson, U.; Wennerström, H. Surface Forces in Bicontinuous Microemulsions: Water Capillary Condensation and Lamellae Formation. Langmuir 1997, 13, 3331-3337.

(39) Waltermo, Å.; Claesson, P. M.; Johansson, I. Alkyl Glucosides on Hydrophobic Surfaces Studied by Surface Force and Wetting Measurements. J. Colloid Interface Sci. 1996, 183, 506-514.

(40) Forsman, J.; Woodward, C. E.; Freasier, B. C. Density functional study of surface forces in athermal polymer solutions with additive hard sphere interactions: Solvent effects, capillary condensation, and capillary-induced surface transitions. J. Chem. Phys. 2002, 117, 1915-1926.
(41) Butt, H.-J.; Kappl, M. Normal capillary forces. Adv. Colloid Interface Sci. 2009, 146, 48-60.

(42) Dèdinaite, A.; Claesson, P. M. Synergies in lubrication. Phys. Chem. Chem. Phys. 2017, 19, 23677-23689.

(43) Álvarez-Asencio, R.; Pan, J.; Thormann, E.; Rutland, M. W. Tribological Properties Mapping: Local Variation in Friction Coefficient and Adhesion. Tribol. Lett. 2013, 50, 387-395.

(44) Dedinaite, A.; Thormann, E.; Olanya, G.; Claesson, P. M.; Nyström, B.; Kjøniksen, A.-L.; Zhu, K. Friction in aqueous media tuned by temperature-responsive polymer layers. Soft Matter 2010, 6, 2489-2498.

(45) Thormann, E.; Bodvik, R.; Karlson, L.; Claesson, P. M. Surface forces and friction between non-polar surfaces coated by temperatureresponsive methylcellulose. Colloids Surf., A 2014, 441, 701-708. 